\title{
TÉCNICAS DE PODER, EFEITOS DE VERDADE E MODOS DE SUBJETIVAÇÃO NO
} ENSINO DA GEOGRAFIA

Técnicas de poder, efectos de verdad y modos de subjetivación en la enseñanza de la Geografía

Techniques of power, effects of truth and modes of subjectivation in the teaching of Geography

Bruno Nunes Batista

Professor no Instituto Federal Catarinense (IFC)

brunonunes.86@hotmail.com

Artigo enviado para publicação em 31/05/2018 e aceito em 18/08/2018

DOI: $10.12957 /$ tamoios.2018.34620

\section{RESUMO}

Analiso neste texto o ensino de Geografia através da perspectiva dos estudos foucaultianos, numa tentativa de responder à seguinte pergunta: que produção de subjetividade vem sendo feita por esse discurso? Tomando por base conceitos e reflexões provenientes do Pós-estruturalismo, procuro a) problematizar os enunciados mais presentes na Geografia no que se refere à formação de sujeitos ideais; b) regressar até um arquivo da primeira metade do século XX, com o objetivo de entender de onde vêm essas práticas discursivas; c) descrever as principais teleologias presentes nelas; d) discutir a manutenção dessas palavras-mestras até a contemporaneidade, interligando-as ao que conhecemos por neoliberalismo; e) levantar possíveis implicações desse pensamento nos currículos escolares.

Palavras-chave: Ensino de Geografia; subjetividade; neoliberalismo.

\section{RESUMEN}

En este texto la enseñanza de Geografía a través de la perspectiva de los estudios foucaultianos, en un intento de responder a la siguiente pregunta: ¿qué producción de subjetividad viene siendo hecha por ese discurso? Tomando por base conceptos y reflexiones provenientes del Post-estructuralismo, procuro a) problematizar los enunciados más presentes en la Geografía en lo que se refiere a la formación de sujetos ideales; b) regresar hasta un archivo de la primera mitad del siglo XX, con el objetivo de entender de dónde vienen esas prácticas discursivas; c) describir las principales teleologías presentes en ellas; d) discutir el mantenimiento de esas palabras maestras hasta la contemporaneidad, interconectando a lo que conocemos por neoliberalismo; e) plantear posibles implicaciones de este pensamiento en los currículos escolares.

Palabras-clave: Enseñanza de Geografí; subjetividade; neoliberalismo.

\section{ABSTRACT}

I analyze in this text the teaching of Geography through the perspective of the Foucaultian studies, in an attempt to answer the following question: what production of subjectivity has been made by this discourse? Based on concepts and reflections from Post-structuralism, I try to a) problematize the most present statements in Geography with regard to the formation of ideal subjects; b) return to a file from the first half of the twentieth century, in order to understand where these discursive practices come from; c) describe the main teleologies present in them; d) to discuss the maintenance of these master words to contemporaneity, interconnecting them to what we know by neoliberalism; e) raise possible implications of this thinking in school curricula.

Keywords: Teaching Geography; subjectivity; neoliberalism. 


\section{PENSAR A GEOGRAFIA ESCOLAR COMO DISPOSITIVO DE PRODUÇÃO}

O ponto central do texto que se inicia é discutir a invenção do que entendemos por sujeito, tomando como pano de fundo a instituição escolar.

$\mathrm{Na}$ linha de trabalho que desenvolverei, o sujeito se trata de uma fôrma idealizada, a fim de engendrar uma subjetividade padronizada e que, para tal objetivo, fez emergir um diferente modelo de escola. Essa, por seu turno, teria a intenção de fabricar indivíduos em consonância com os ideais iluministas da ordem, do progresso, da liberdade, da razão e do trabalho.

Coloco-me ao lado daqueles que entendem que o sujeito não é uma força que se constitui a priori a partir das suas características pré-existentes, mas um objeto a ser edificado, formado e enformado pela escola. Sua origem não é, portanto, inata, mas advém "[...] dos arranjos históricos que engendraram o pensamento de uma época" (VEIGA-NETO, 1995, p. 12). Conforme nos explica Silva (1995), apostando em raciocínio parecido, "O sujeito moderno, longe de constituir uma essência universal e atemporal, é aquilo que foi feito dele. Sua apresentação como essência esconde o processo de sua manufatura" (p. 248-249).

Com essa postura de trabalho assumida, posso então dizer a que estou vindo neste texto. Primeiro de tudo, não tomarei a escola como um aparelho de reprodução ou falseamento da realidade, mas enquanto dispositivo de produção, uma "[...] eficiente e ampla maquinaria encarregada de formar o que se denomina o sujeito moderno e, por aí, de formar o próprio mundo moderno" (VEIGA-NETO, 2003, p. 213). Em segundo lugar, através do pressuposto segundo o qual a subjetividade não se daria pela história, a epistemologia ou a autoria - como diziam Freire, Piaget e Morin, respectivamente mas de fora para dentro, o que estou dizendo é que o sujeito é aquilo que se faz dele por meio de relações de poder; ele é, por conseguinte, aquele que se sujeita e/ou é assujeitado. Por isso, em terceiro lugar, coloco-me ao lado das perspectivas pósestruturalistas que têm nos estudos de Michel Foucault sua pedra de toque. Por último, o recorte analítico que me disponho a tencionar: o ensino de Geografia. Linha de pesquisa que se propõe a entender e desenvolver trabalhos sobre um componente curricular presente desde o século XVI na escola brasileira, não penso que ela esteja alheia às contingências históricas e políticas que, ano após ano, vêm demandando um determinado tipo de sujeito, para um dado projeto de sociedade. É nessa esteira que o texto irá se desenrolar.

Partindo de uma questão do presente, isto é, que subjetividades o ensino de Geografia vem desejando tatuar em seus alunos e professores, deslocar-me-ei até arquivos mais antigos desse campo do conhecimento para, daí então, discutir algumas das raízes do discurso pedagógico contemporâneo, além de pôr em pauta a que poderes elas estariam servindo.

\section{MÉTODO...}

O que mais vem me interessando é pensar o ensino de Geografia como um discurso que pressupõe, como ponto de partida, um ordenamento coercitivo de linguagem. A partir de Foucault (2008), entendo um discurso como algo que forma os objetos sob os quais se refere, a partir de uma série de preceitos; nesse sentido, não existiria a realidade verdadeiramente verdadeira cuja apreensão seria dada pelo conhecimento, mas, nessa perspectiva, uma materialidade que passa a existir através dos modos pelos quais nos pronunciamos perante ela. E esses modos também não seriam os únicos e nem mesmo naturais, mas os resultados de um campo de batalhas entre 
relações de poder e saber. Não por acaso, Foucault dizia que uma prática discursiva "[...] é essencialmente estratégica; estabelecemos discursos e discutimos, não para chegar à verdade, mas para vencê-la. É um jogo: quem perderá, quem vencerá"? (2002, p. 140).

Ao considerar o ensino de Geografia enquanto um discurso na perspectiva foucaultiana, valeria analisar no seu interior o que se fala mais, como se fala, quem fala e em que lugar se deve estar para poder falar sobre tal saber; em suma e como pessimistamente escreveu Foucault (1996, p. 9), acatar que "[...] não se tem o direito de dizer tudo, que não se pode falar de tudo em qualquer circunstância, que qualquer um, enfim, não pode falar de qualquer coisa". Trata-se de tomar a verdade geoescolar como uma produção essencialmente histórica, totalmente deste mundo e mergulhada em intencionalidades; portanto, uma reflexão sistemática que não está no alcanço de encontrar doutrinas absolutas para o trabalho pedagógico na ordem da Geografia, nem em, de maneira panfletária, colocar-se a favor ou contra ela. O objetivo é transformar o ensino da Geografia em um conjunto de documentos e, a partir daí, vê-los pela sua exterioridade. Com efeito, essa abordagem apanha a contingência que se concatenou ao priori histórico e procura entender como isso se propagou em termos linguísticos. Primazia dada aos sistemas de linguagem, pois são eles que determinam o que é considerado verdade, posto que se falamos e pensamos sobre ensino de Geografia de um determinado jeito, isso se desenrolou pelos discursos hegemônicos que nos foram disponibilizados. Assim, fomos limitados pela linguagem subjacente à nossa formação profissional, que nos foi imposta, cabendo-nos apenas reprisá-la a partir de uma formação discursiva com ordenamento fixado.

Com a centralidade analítica deslocada para o discurso, e na vontade de entender quais foram as subjetividades produzidas no ensino de Geografia por essa prática, uma das minhas intenções vêm sendo identificar a genealogia dos dizeres que prescrevem certos deveres necessários no que tange à formação de sujeitos. Isso me coloca na posição, por exemplo, de suspeitar de certas palavras de ordem bastante repetidas - e até mesmo repetitivas... - que são pronunciadas contemporaneamente. Naquelas que aqui me interessam mais, seria interessante desnaturalizar a sucessão de dizeres em prol de um ensino de Geografia que forme sujeitos ativos e autônomos, que defendem a diversidade e lutam pela justiça social e a igualdade (CAVALCANTI, 2011; 2012); alunos críticos e protagonistas, que se dão conta das contradições da realidade e procuram transformá-la (VESENTINI, 2004); uma educação integral que almeja a formação de cidadãos, que enxergam a realidade como materialidade complexa e indissociável, pois o lugar faz parte do mundo e a partir daquele se constrói esse (CALLAI, 2009); processos de ensino e aprendizagem que colocam os alunos como protagonistas e autores, que interferem no cotidiano e não aceitam explicações falsas e reducionistas da realidade (CASTELLAR, 2011; COSTELLA \& REGO, 2011).

Ora, todas essas teleologias, nos seus princípios de formação, têm uma regularidade sólida e fazem parte, como já defendi em outros lugares (BATISTA, 2017a; 2017b; 2018a), de um dos pilares da ordem do discurso geoescolar cujo nome provisório batizei de Redenção. Com efeito, é possível dizer com segurança que a formação discursiva do ensino de Geografia conduz seus pesquisadores a comumente escreverem à guisa de finalismo, visando um ideal utópico de sociedade e de sujeito: enunciados infestados, por sua vez, daquilo que Veiga-Neto (2012) alcunhou de pragas pedagógicas, como o messianismo, o salvacionismo e o prometeísmo. No entanto, mais do que assinalar uma identidade de ditos e escritos, é profícuo cogitarmos como esses objetos discursivos foram colocados lá e a partir de que momento ganharam autoridade 
inquestionável; ou seja, entender as suas condições de existência e o seu estatuto de formação de saberes.

Uma atividade que me vem sendo enriquecedora é regressar até textos pedagógicos da primeira metade do século XX sobre ensino de Geografia e tomá-los na sua organização enquanto um arquivo, isto é, aquele conjunto total de discursos pronunciados em uma determinada época e que continuam se fazendo presentes (FOUCAULT, 2000). Entre esses arquivos, ando utilizando-me de um em especial: o Boletim Geográfico. Trata-se de uma publicação do Instituto Brasileiro de Geografia e Estatística (IBGE) que circulou nos espaços acadêmicos e técnicos entre o ano de 1943 (data da sua primeira edição) até 1978 e que, de maneira inédita à época, continha um espaço reservado ao ensino de Geografia denominado "Contribuição ao ensino". Com uma tiragem média de 10 mil exemplares por edição e preço considerado acessível constituiu, até 1978, a expressiva marca de 35 anos de editoração transmitidas por intermédio de 259 publicações.

A partir da descrição dos textos pedagógicos presentes no Boletim Geográfico, por meio da questão condutora "Que tipo de sujeito o ensino de Geografia deveria forjar?", cheguei a algumas linhas gerais de trabalho que fizeram deste periódico um lugar seguro de produção de discursos, enunciados e estratégias de linguagem; localidade singular que instituiu algumas das maneiras determinadoras acerca de o que se deve e como se deve escrever sobre a Geografia escolar.

Nas seções seguintes, descreverei através de três compartimentações argumentativas quais seriam os sujeitos a serem formados pelos estudos geográficos nas páginas do período em questão. Na primeira delas, apresento a visão dos autores sobre como os alunos poderiam integrar-se à sociedade, envolvendo desde questões básicas como localização, até uma consciência planetária; na esteira dessa ação, mostrarei como esses estudantes, pelos conteúdos, desenvolveriam questões de hábitos, pesquisa e comportamento; finalmente, integro as ideias dos autores do Boletim Geográfico às atitudes requeridas de sujeitos para que fossem comprometidos, críticos e cidadãos.

\section{PRINCÍPIO ONTOLÓGICO}

Os conteúdos geográficos possibilitam que o sujeito se insira no mundo de maneira qualificada, transformando a realidade tanto a partir dos seus interesses imediatos quanto em prol dos bens coletivos. Lema redentor, de forte carga emocional, que sombreia com intensidade o discurso do ensino de Geografia contemporâneo. É importante sublinhar que, no entanto, sua força data de dias anteriores e, nesse sentido, muitos textos do Boletim Geográfico são profícuos substratos.

Essa é um tipo de posicionamento que podemos encontrar no texto de La Blache (1943), para o qual não cabe à Geografia a exposição vazia de um lugar geográfico qualquer, mas instigar no aluno o desejo de "[...] saber onde ele se encontra, em que parte do globo, em que posição em relação a que eles ocupam, em que condições de extensão e distância em relação com aquelas que podem apreciar diretamente por si próprios" (LA BLACHE, 1943, p. 18). Desloca-se a didática da ação que enumera e nomeia, para aquela que faz o estudante sentir-se interessado por localidades diferentes das suas, e que, enquanto isso, encontram-se interconectadas. É daí que, como explica Carvalho (1945), o aluno consegue ter uma visão de conjunto que abarca um quadro social e natural completo; trata-se de "[...] preparar o estudante a compreender a sua posição individual, relativa a um ambiente mais próximo, dando-lhe sentido de direção, do quadro geográfico imediato visível e próximo invisível, além do horizonte" (CARVALHO, 1945, p. 9). Assim sendo, o aluno vai relacionando o seu lugar a locais 
distantes, fazendo movimentos de raciocínio não só concêntricos, mas alternando um vai-e-vem geográfico que lhe dá sentido aos elementos da paisagem e o faz orientar-se no seu espaço cotidiano sem obscurecer o fato de que este pertence à lógica global: um trabalho pedagógico no qual se vai e volta do perto ao distante, do particular ao geral, do que se é concreto para o que seria abstrato (BACKHEUSER, 1946). Como resultado, o aluno vai se integrando conscientemente à "grande comunidade humana", o que o faz ter responsabilidades e deveres globais, sendo um cidadão do mundo, com mentalidade mundial (FICHEUX, 1950a). A bom termo, ser um cidadão do mundo é colocar as informações geográficas que recebe sob um "[...] crivo de uma crítica severa" (FICHEUX, 1950a, p. 233).

Carvalho (1952c) prossegue: a ideia é alavancar um intercâmbio internacional, visando o entendimento acerca da interdependência dos grupos, o que não se resumiria às relações produtivas capitalistas, mas, principalmente, à responsabilidade ambiental coletiva. A Geografia deve "[...] demonstrar a necessidade de conservar as riquezas da terra, de fazê-las servir às necessidades humanas com economia, restaurando-as, na medida do possível, quando atingidas pela economia destrutiva" (CARVALHO, 1952c, p. 598). É como nos ensina Cabral (1958); segundo ela, o ensino de Geografia tem que problematizar o intenso uso do solo, cuja conservação não é apenas questão teórica, mas um alerta de que, em algum momento, pode esgotar-se e deixar de produzir os bens necessários.

Por tais perspectivas é que a Geografia escolar iria se justificar, ou seja, desenvolvendo integralmente seus alunos, capacitando-os a viver em comunidade e a trabalhar dignamente em prol do progresso humano (FONSECA, 1955). Com efeito, os estudos geográficos devem construir pontes através das quais os povos possam aproximar-se, um movimento de irmandade que se encontra na base das relações humanas. Por conseguinte, é função do professor defender a "[...] fraternidade humana universal" (CABRAL, 1958, p. 542). Isso porque, segundo aponta Carvalho (1960), se existe um caminho pelo qual fosse possibilitada a conservação global dos recursos naturais e o relacionamento pacífico entre as populações, ele está na construção da ideia de interdependência e intercâmbio, no intuito de alcançar a inteligência sábia perante as riquezas da natureza. $\mathrm{O}$ ensino de Geografia, por ter um compromisso ético com a comunidade mundial, questiona os valores predominantes alicerçados na contradição capitalista de produção e, logo, deve criar condições pedagógicas para forjar um aluno "[...] consciente da vida de todos os dias, instruindo-o a respeito dos acontecimentos e sua significação, para despertar entre os povos o desejo de cooperação" (CARVALHO, 1960, p. 459). Ou, dito de outro modo por Almeida, "[...] facilitar o aparecimento da compreensão e boa vontade tão desejadas para uma paz universal, um mundo em que realmente se pudesse dizer: somos todos irmãos" (1962, p. 212). A formação não teria outra alternativa a não ser a de buscar a integralidade. $\mathrm{O}$ aluno precisa colocar-se como um "[...] elemento ativo da sociedade, que umas tantas coisas que faça ou deixe de fazer irão prejudicá-lo ou a seus descendentes próximos ou remotos" (ALMEIDA, 1962, p. 213); pensando e agindo de maneira integrada, ele vai (e volta) de um sentido estrito (o bairro, o município, o Estado, o país), ao lato (o mundo, o universo). Um autor da época nos oferece uma segura síntese dessas obrigações geoescolares:

a) produzir a compreensão dos fenômenos físicos e humanos por todo o mundo;

b) fazer com que os jovens compreendam e admirem os esforços de todos os povos, para o aperfeiçoamento de sua civilização criando um ideal de fraternidade internacional; 
c) preparar os educandos para uma vida em comunidade, graças ao trabalho de grupos. (CUNHA, 1962, p. 426).

Não por acaso, Padilha (1963) apregoa que os educandos têm que ir sentindo apreço pelo trabalho socializado e democrático, no qual elaboram no coletivo propostas de intervenção geográfica alinhadas a um espírito de respeito mútuo, sem que o poder esteja concentrado nas mãos dos seus professores ou de alguns colegas. Esses jovens, logo, terão condições de pensar criticamente problemas sociais e ambientais em múltiplas escalas, porquanto serão conscientes "[...] do valor do trabalho humano e da cooperação, e criando, paralelamente, sentimentos de respeito em relação a todos os povos do mundo em que convive" (PINTO, 1964a, p. 114). Por tudo isso, o professor de Geografia não pode esquecer da responsabilidade que lhe cabe de "[...] despertar no educando a consciência de que todos somos membros de comunidades, integrando-o, aos poucos, na vida, bem como o despertando sobre a necessidade da cooperação internacional, apesar das diferenças geográficas existentes" (DAMASCENO, 1965, p. 319). Afinal, ao estarem cientes desse relacionamento, poderão organizar melhor o uso e apropriação da natureza e dos territórios, o que tanto levaria a uma maior pacificidade quanto à manutenção inteligente dos recursos naturais. Justamente por isso, não poderia existir outros caminhos nas aulas que não aquele que operacionalizasse uma Geografia "[...] encarada com sentido dinâmico e visão de futuro, a fim de que quem a estude se inteire da grande tarefa atual dos seres humanos na construção, em diferentes escalas, do mundo do futuro" (ZAMORANO, 1969, p. 117). O aluno, sobremaneira, deve perceber-se como detentor de uma intransferível responsabilidade perante o seu lugar geográfico, que também é mundo.

Estamos vendo, em voo alto, algumas das potencialidades subjetivas que poderiam ser alavancadas pelo ensino de Geografia no Boletim Geográfico. Objetivomotriz: fazer os alunos autores dos processos de ensino e aprendizagem, transformadores da realidade. Desde as mais tenras idades, incentivar-se-ia a cidadania planetária, comprometida com as prementes questões ambientais e disposta a solucionar problemas de múltiplas dimensões, do local ao global, lugar-mundo. Novos sujeitos estavam sendo requisitados por outro mundo que parecia anunciar-se: interconectado e, por isso mesmo, problemático. Pelas suas características internas, não haveria como não estar a Geografia incluída no papel de produzir essas novas personalidades. Os moldes de manufatura subjetiva já estavam, como cláusulas naturais, à disposição.

\section{TIPO IDEAL}

Aqueles que pensavam o ensino de Geografia no periódico que estamos analisando projetavam uma sociedade idealizada que tinha na existência de sujeitos disciplinados, flexíveis e criativos seu principal diferencial. No cotidiano da sala de aula, tal premissa demandaria sensíveis modificações, pois isso significaria que os conteúdos deveriam ser usados de uma certa forma, por dados sujeitos, para determinados fins. Na esteira desse macroprocesso, prescrições foram tabuladas.

Uma delas se referia à iniciação científica: por meio do seu uso, aplicado à resolução de problemas do lugar, o ensino de Geografia faria do aluno "[...] um cidadão útil à comunidade" (PINTO, 1964a, p. 114). Ancorados no espírito da cientificidade, os fatos mais simples e discretos do cotidiano são passíveis de melhoria qualitativa; nesse sentido, a iniciação científica é fundamental, pois o aluno de Geografia, "[...] ao mesmo tempo que adquire a experiência do mundo onde terá de viver e agir quando adulto, exercita a sua faculdade, adquire hábitos mentais que o habilitará mais tarde a observar, 
a julgar com lucidez e com espírito crítico e compreensivo tudo que vir em torno de sua pessoa" (FICHEUX, 1950c, p. 387). Consequentemente, a Geografia é menos descritiva e mais investigativa.

Carvalho (1952b) se debruçou sobre a validade do método científico no cotidiano escolar e permitiu-se dar algumas sugestões de aplicabilidade. Segundo seu ponto de vista, a construção do pensamento científico na escola se dá pela motivação do estudante, que ocorre na medida em que a sua curiosidade é tanto valorizada quanto atiçada. A partir dessa premissa, que indiscutivelmente possui um caractere de ludicidade, a ciência vai estar atrelada às chances que o professor dará para que o cotidiano seja modificado pela turma. Neste retrabalhar estão contidos aspectos intervencionais, que acontecem quando as sequências didáticas procuram "[...] a tendência à auto expressão criadora" (CARVALHO, 1952b, p. 232). Bem ao contrário de serem colocados no papel de receptores de informações, os alunos realizam investigações eivadas de protagonismo, intervencionismo e participação coletiva. Nesse movimento pedagógico, alimentado pelos melhores princípios das pedagogias ativas, "[...] jamais o aluno permanece passivo; o que aprendeu assim conserva com maior facilidade. Exercitou a sua inteligência, sobretudo, seu senso de pesquisa, sua curiosidade intelectual" (MEYNIER, 1954, p. 444-445).

O que podemos perceber é que foi ganhando espaço no Boletim Geográfico uma concepção de ensino que tomava como trampolim de ensino e aprendizagem a vida nas suas características materiais e subjetivas, e é exatamente por isso que a iniciação científica ganharia centralidade, posto que se alicerçava na dimensão integral do aluno. Preocupação de autores como Santos (1964), Cunha (1962), dentre outros, querer-se-ia que o aluno assumisse responsabilidades e propusesse encaminhamentos resolutivos; ora, que ele refletisse acerca do "[...] meio em que vive através da compreensão dos problemas e dos valores, da realidade nacional e das peculiaridades regionais" (PINTO, 1964b, p. 396). Com a clareza de um método que observa, generaliza e recapitula, é possível ao estudante "[...] responder aos comos e porquês e, em suma, dedicar-se a trabalhos de análise e sínteses" (ZAMORANO, 1969, p. 121). Simultaneamente científico e com personalidade integral, eis o cidadão idealizado a ser evocado pelos estudos geográficos na Escola Básica. Um sujeito que vai se autodisciplinando e fomentando sua criatividade na busca de melhorar a sociedade em que vive e que, na esteira isso, qualifica coletivamente a grande comunidade que é o mundo.

$\mathrm{Na}$ esteira desses princípios formativos, Pedroso (1966) sugere que o professor recrie na sua instituição um clube geográfico, representação em menor escala da complexidade que é a vida em sociedade. Quando os alunos se reúnem em espaços como esse, o espírito de cooperação é instigado, ainda mais que, pensando no prol do coletivo, eles têm oportunidades para exercer sua iniciativa individual. De forma semelhante, a manutenção do local possibilita que os alunos deem valor à vida em comunidade e ao patrimônio público; esse equilíbrio almeja "[...] proporcionar ao estudante alguma experiência de vida democrática, colaborando, destarte, na formação do futuro cidadão" (PEDROSO, 1966, p. 591).

Como pano de fundo à escrita da seção "Contribuição ao ensino", havia, de um lado, um mundo pacífico e integrado, prenúncio do que viria a ser chamado de globalização; os alunos seriam exortados a construir uma consciência de totalidade, concebendo as culturas como interdependentes e os recursos naturais como elementos a serem explorados com cautela, visto que suas fronteiras extrapolavam os limites artificiais impostos pelos Estados. Por outro lado, os sujeitos requisitados pelo século XX eram responsáveis pelas suas comunidades. Em alguns textos do Boletim Geográfico de maneira mais contundente, em outros de forma panorâmica, o fato é que 
a ideia de responsabilidade coletiva pela totalidade que se é o mundo era ponto pacífico nas discussões. Caberia à Geografia escolar, como saber transversal, dar conta de formar esses sujeitos que se localizavam no mundo à maneira de pertencimento. Os alunos, uma vez comprometidos nas complexas questões globais, deveriam construir habilidades para fazerem intervenções qualitativas nessas mesmas questões. Como pessoas disciplinadas e criativas, nas suas mãos pairavam o devir científico e tecnológico tão necessário ao mundo problemático com o qual se deparavam. $\mathrm{O}$ ensino de Geografia deveria contribuir para que os alunos produzissem conhecimentos novos a partir das condições materiais existentes; que fossem estimulados a desde cedo adquirirem iniciação científica e gosto pela inovação. Pequenos cientistas, nada mais e nada menos.

\section{POSTURA-PADRÃO}

Quando os artigos sobre Geografia escolar no Boletim Geográfico procuravam enfatizar que o ensino informativo deveria ser substituído pelos valores formativos, os autores referiam-se a forjar sujeitos que fossem críticos, pois apenas através de uma postura de questionamento do espaço geográfico tanto a cidadania poderia ser exercida quanto o comprometimento com a pátria e o mundo tornar-se-ia atividade básica. A crítica significava uma atitude de reflexão, um descontentamento com a informação simples que não era problematizada pelo aluno; ele deve se sentir incomodado com algum dado recebido e procurar investigá-lo. Como resultado, tanto se descartava o determinismo geográfico simplório quanto, em sentido inverso, entendia-se a realidade como produto de conexões diversas, que não a fazem inexorável, mas em transformação perene.

Nesse seguimento, o aluno crítico deseja melhorar o seu meio, um corolário de um compromisso afetivo e social do qual é parte indissociável. Com efeito, a Geografia deve clarificar ao estudante uma percepção na qual ele não se vê como centro do mundo, mas ator descentrado e atento a outros pontos de vista, compreendendo "[...] a realidade do mundo com suas exigências e possibilidades, e da mesma forma os deveres que incumbem a juventude para com o futuro" (FICHEUX, 1950b, p. 611). Levando em conta que são os "[...] os problemas da vida humana que justificam os estudos geográficos e que, por conseguinte, os devem guiar" (CARVALHO, 1952c, p. 597), a escola precisa aproximar-se dos processos que dão sentido à vida, fundada num pressuposto de consciência social; qualquer estudo geográfico, com efeito, deve estar compromissado com a ideia de cooperação mútua e solidariedade global. Ao colocar que "A distribuição geográfica das riquezas e do poder é de impressionante instabilidade" (p. 598), Carvalho (1952c) apontava para a aprendizagem geográfica pensada como um ato de respeito à diversidade.

É claro que, nessa linha mestra de raciocínio, não se autorizava à Geografia que subtraísse das suas preocupações educacionais questões de cunho social, político e econômico; no âmbito local, alinhadas com uma ideia de civismo; na perspectiva global, com pressupostos éticos-morais (MONBEIG, 1955). É por esses motivos - que visam trabalhar pelo progresso e melhora planetária - que a Geografia deve possuir presença cativa entre os componentes curriculares da educação básica. Ora, "Se queremos cidadãos que sejam do mundo atual, e não do mundo de ontem; se quisermos ter cidadãos preparados para ajudar a resolver os problemas do Brasil" (MONBEIG, 1955, p. 426), os estudos geográficos devem ser celebrados ao invés de deslegitimados. Basta identificar o solo moral sob o qual se erigia o artigo de Cabral (1958), ao pontuar a obrigação de "Despertar e desenvolver o amor à pátria, e, através do estímulo ao 
sentimento americanista, levar o aluno a um sadio propósito de compreensão e fraternidade universal" (p. 543). Ou a validade das metodologias participativas defendidas por Weiss (1961), que integravam os sujeitos às comunidades ao mesmo tempo em que os tornavam hábeis na capacidade de modifica-las.

Com essas premissas, é evidente que não era há tempos o caso de se propor, no Boletim Geográfico, a modelagem de "[...] de formar geógrafos-mirins, especialistas em agrotecnia, mas sim fazer com que o aluno pudesse participar da vida que o cerca" (WEISS, 1961, p. 252). Sujeitos interdisciplinares e globalizados, conscientes de que o seu lugar geográfico e cultural não é nem melhor nem pior que qualquer outro, mas diferente; lugares que, mesmo distantes, carregam conexões que os fazem interdependentes da grande rede planetária. Sujeitos críticos, que não romantizam a realidade, o Estado e o país, mas procuram vê-los como eles são, nas suas contradições e injustiças; e que, na esteira dessas constatações, irão debruçar-se em crucias temáticas para resolvê-las, arrefece-las, transforma-las. Em suma, é responsabilidade do professor Geografia "[...] educar seus alunos preparando-os para exercerem com utilidade suas obrigações de cidadania" (WEISS, 1961, p. 239). Espécie de missão a fim de engendrar um pináculo de sociedade, tem-se que aproximar a realidade da escola, sem maquiagens ou deformações ideológicas, para ligar o educando ao mundo em que vive e credenciálo a "[...] aliviar e combater os preconceitos raciais, e religiosos, dar a sensibilidade pelos problemas das classes menos favorecidas" (WEISS, 1962, p. 301).

Em torno dos "[...] grandes problemas da fome, da miséria, da elevação do nível de vida e o aprimoramento espiritual dos indivíduos" (ZAMORANO, 1969, p. 119), em menor ou maior grau, a Geografia escolar surgia como elemento crucial para a formação de uma melhor sociedade. As frentes de ataque eram tão diversas quanto complexas: a questão ambiental, a concentração de terras, a conservação dos solos (PADILHA, 1963); a desigualdade social e econômica na sociedade brasileira (PEDROSO, 1966); a melhora da condição humana (FONSECA, 1955). Com o que vimos até aqui, parece que já podemos inferir sob quais auspícios os teóricos da Pedagogia geográfica escolar organizavam suas matrizes argumentativas. Ao se referirem com rigor à formação de sujeitos regrados pelos valores democráticos mais nobres, não tomaram apenas para si tais caminhos prescritivos. É fato que, por aqueles dias, professores e alunos passaram a receber, sem que soubessem ou sequer tivessem pedido, uma pesada bagagem de atribuições morais com as quais, a partir de então, deveriam aprender a lidar naturalmente, prestar continência aos seus valores mais elevados, às suas melhores promessas de salvação educacional.

\section{PROBLEMATIZANDO O DISCURSO POSTO}

Já me aproximando do final, gostaria de, antes, fazer duas constatações, seguidas de uma pergunta geral com breves apontamentos.

Em primeiro lugar, uma questão de cuidado teórico que me parece pertinente. Existe um consenso na academia brasileira, no que toca ao ensino de Geografia, de que esse poderia ser entendido através de fixadores temporais, que delimitariam um período tradicional e conservador interrompido por uma abordagem crítica e pedagogicamente contemporânea. Bandeiras levantadas em textos como os de Cavalcanti (2008) e Castrogiovanni (2007), tratam-se de ferramentas fracamente operatórias, que denotam um desconhecimento do amplo percurso do pensamento geográfico escolar. Cavalcanti, por exemplo, refere-se ao que chama de renovação durante os anos 1990, em que passou a primeiro plano a preocupação de "[...] atribuir significado à Geografia que se ensina para os alunos, tornando-a mais interessante e mais atraente e possibilitando seu 
aprendizado por eles" (2008, p. 23); já Castrogiovanni retrocede alguns anos nas suas linhas divisoras e vai até 1978, num encontro de geógrafos realizado em Fortaleza, para encontrar a inauguração do método investigativo da Geografia crítica, em que tanto o espaço passa a ser concebido na sua totalidade, quanto, por outro lado, procura-se denunciar as suas contradições (CASTROGIOVANNI, 2007, p. 38-39). O equívoco desses autores, como vimos, é duplo, posto que registros históricos como aqueles materializados no Boletim Geográfico dão relevo à ideia de uma educação complexa, politizada e socialmente comprometida antes desses marcadores de tempo escolhidos; ora, a própria centralidade no aluno e na sua aprendizagem como motores da construção do conhecimento não vem de agora, mas de uma longa marcha que tem nas pedagogias ativas e participativas da primeira metade do século XX evidentes comprovações (VIDAL, 2003, 2013; XAVIER, 2002). Fixar um ponto de origem para qualquer transformação social que seja, por sua vez, soa tão problemático quanto as posturas anteriores, não apenas devido ao fácil rebatimento, mas porque, no meio desses movimentos, a reboque vêm junto ídolos e lideranças, que teriam conduzido as massas em direção ao saber ético, justo, belo e verdadeiro.

Em segundo lugar, um leitor costumeiro de textos sobre ensino, em geral, e Geografia, em particular, não encontraria dificuldades para assinalar as semelhanças de família entre o que se diz e escreve na contemporaneidade e aqueles dizeres preconizados no Boletim Geográfico. No que tange à produção de subjetividades, o quadro, a rigor, não se alterou. Permanecemos à procura das melhores maneiras de formar sujeitos críticos, protagonistas, autores e ativos. Mantivemos a instrumentalidade, para tal, orbitada ao redor das psicopedagogias ativas e das didáticas participativas. Continuamos à espera de um futuro melhor, no qual passaríamos de eterno país em desenvolvimento para nação desenvolvida. De modo que, a valer, os contrastes entre os pesquisadores do ensino de Geografia vêm sendo, muitas vezes, apenas de vocabulário, organização textual ou sugestão de recursos didáticos. Nada de novo sob o sol. Engano daqueles que pensam se tratar tudo isso, no entanto, de mero conformismo intelectual. Para entendermos a estabilidade desses slogans no interior das práticas discursivas do ensino de Geografia, cabe realizar três últimos questionamentos, cujas respostas relacionadas à infância, à subjetividade e ao discurso sinalizam-nos frutíferas perspectivas de trabalho.

\section{QUAL SERIA A GENEALOGIA POSSÍVEL PERANTE O ENSINO DE GEOGRAFIA?}

Para começo de conversa, é preciso apontar panoramicamente o percurso histórico do saber pedagógico em relação à noção de infância.

Conforme Ariès (1981), é a partir de um passado recente, cuja datação não vai muito mais longe que o século $\mathrm{XV}$, que a crianças foram tornando-se objeto de preocupação e ação moral dos adultos, através de uma inflexão que não tem um marco de fundação, mas que foi se dando por meio de uma série de mudanças. Para corroborar o que chama de a "invenção da infância", esse autor coloca que no período medieval não existia sentimento de cuidado com relação às crianças, vide a análise que faz de pinturas dos séculos XII e XIII, em que são identificadas características nas quais as crianças usam roupas de adulto ou aparecem musculosas. Com efeito, tratava-se de uma preocupação de, no máximo, leva-las à tenra idade, estado no qual seriam consideradas como "pequenos adultos" ou "adultos em miniatura". Por conseguinte, uma vez superado o risco eminente de mortalidade infantil, elas já eram colocadas num processo produtivo, para ajudar seus pais em atividades agrícolas, como colheitas, preparo de 
hortas, etc. Essa perspectiva é posta em xeque em meados do século XVI, quando as crianças se transformam em objeto que deve ser paparicado. É a fase, diz Ariès (1981), no qual são parte das brincadeiras da família. Nesse período, contudo, ainda não aparecem os instrumentos que evocavam a correção, a educação e a condução da criança.

Para que, de fato, fossem concretizadas as condições de possibilidade para que a infância pudesse ser elencada em um campo de visão, uma prática de discurso e um estágio a ser policiado, seria necessário esperar as efervescências cotidianas intensificadas a partir do século XVII. Estamos falando, dentre outros acontecimentos, de eventos como a constituição dos Estados Modernos, a divisão social do trabalho, a explosão demográfica nas cidades, os incipientes movimentos de concentração capitalista, a manutenção de propriedade privada, a Reforma Protestante e a Revolução Industrial (DURKHEIM, 1994). Entre outras subjetividades, para aquelas que aqui mais nos interessam seria fundamental inventarem-se maneiras através das quais fosse possível anular a criança no seu sentido de figura histórica desprezada, para substituí-lo pelo emblema de figura moral infantil, "[...] promessa antecipada, profecia realizada, mito moral em que o humano racional se garante de si próprio: criança feliz = mundo feliz/infância melhor = mundo melhor" (CORAZZA, 1998, p. 37). Consequentemente, é enquanto objeto de cura que a infância começava a ser discutida.

Nesse grande e fragmentado movimento histórico, múltiplos dispositivos religiosos e pedagógicos foram criados com o intuito de fazer aflorar nos frágeis infantis o que eles teriam de mais nobre; pressuposto, todavia, incompatível com as rédeas familiares: daí emerge um dos mais importantes embriões do princípio da escolarização em massa, prática obrigatória. Segundo clarifica Corazza (1998, p. 206), "Para crianças doentes de uma humanidade doente, o melhor de todos os remédios é a escola, verdadeira e viva oficina de homens e viveiro eclesiástico, político e econômico. Remédios? São dados a quem está doente".

Temos bons exemplos a título de ilustração. Não mais considerada como miniatura adulta, a criança não poderia misturar-se nas salas de aula com os mais velhos, nem ser tratada como tal; dessa decisão em diante, abriram-se as portas para questões mais detalhadas, como os estágios da infância, que exigiriam uma seriação compreensiva - autores como Rousseau, até certo limite, mas principalmente Piaget, dedicaram esforço futuro a essa questão. Residia nessa intenção de etiquetar os períodos da infância parte de um pressuposto segundo o qual existia uma inocência a ser resgatada, uma conquista a ser realizada utilizando técnicas cuja abrangência sobre o corpo e a mente dos sujeitos infantis esperava-se que fosse total (CORAZZA, 1998).

Afora isso, num espaço no qual muitas crianças conviviam ao mesmo tempo, e de modo não-voluntário, situações como a indisciplina, a falta de motivação e a desorganização das classes vieram à tona. E eis que o mestre, antes alheio a qualquer responsabilidade que ultrapassasse o domínio do conteúdo que lecionava, deparou-se com um novo sistema em que a classe, para agir como tal, deveria ser imbuída de regras e procedimentos. Os mestres-escolas vão atrás de soluções e essas passaram a ser conhecidas no seu conjunto como pedagogia, "[...] um discurso e uma prática de ordem que visam contrapor-se a toda forma de desordem na classe" (GAUTHIER, 2010, p. 133).

Justifico essa não mais do que sucinta retomada com dois argumentos. Inicialmente, para sublinhar a inexistência, na perspectiva em que estou me movimentando, de qualquer sujeito natural, "desde sempre aí" (VEIGA-NETO, 1995), ou com características inatas que num passe de mágica iriam se desenvolver. No que tange ao sujeito infantil, ledo engano, pois foi preciso uma grande mudança de postura 
perante esse estágio da vida humana para, a partir de então, entende-lo como especial e objeto a ser tutelado. Em segundo lugar, porque se assim se deu, não o foi devido a causas teológicas ou acidentais, mas ao contrário, por contingência, decorrida de inúmeros e turbulentos eventos históricos. Em outras palavras: mera necessidade.

Com esse apanhado, a compreensão daquelas linhas de subjetividade que almejavam engendrar os melhores alunos por intermédio do ensino de Geografia no Boletim Geográfico perde em caráter bom samaritano e ganha em eventualidade histórica. Com efeito, se querer-se-ia sujeitos críticos, cientistas, cidadãos e proativos, é devido ao momento ser mais do que propício para tal. Ora, no período de vigência do periódico assistimos aos violentos fluxos migratórios do campo para a cidade, o aumento das taxas de natalidade, a urbanização acelerada e os aquecidos processos de industrialização desencadeados pela substituição de importações em meio às duas grandes guerras mundiais (ROMANELLI, 1986). Assim sendo, se não são totalmente iguais àqueles fatos ocorridos na Europa Ocidental que mudaram o olhar perante a criança e a escola, os múltiplos e combinados eventos no Brasil foram tão transgressores quanto os primeiros e, nesse sentido, podemos dizer que atravessava ambos uma lógica comum que os condicionaria desde então: a da economia de mercado capitalista. Portanto, demandaria com urgência sujeitos habilitados para tal.

\section{PORQUE OS ENUNCIADOS SE REPETEM?}

Simples: por ser ele uma continuidade da Modernidade, o grande projeto do Iluminismo cujas promessas inalcançadas continuam em vigor (BAUMAN, 2011). Segundo Maffesoli (2003), entender a gênese desse amplo movimento filosófico, científico e cultural perpassaria o conhecimento da sua "tríade fundadora", alicerçada no indivíduo, na História e na razão. Para esse sociólogo, como ponto de partida a Modernidade inventou um indivíduo ideal, sujeito autônomo e livre. No entanto, para alcançar esse estágio último da espécie humana ideal, urgia-se que se passasse por uma condução linear teleológica, dos degraus mais baixos aos mais altos, das comunidades mais bárbaras e obscuras às mais civilizadas; história ao modo de narrativa, alavancada pela "[...] grande marcha real do Progresso, desenvolvimento rumo ao Espírito absoluto, graças aos quais a humanidade realizaria a sua reconciliação consigo mesma" (MAFFESOLI, 2003, p. 41). Uma vez historicizado, cabia ao indivíduo sair da menoridade e tornar-se um sujeito esclarecido (KANT, 2012); a ideia da sua finitude supunha empreender uma relação para consigo que o fizesse um espelho melhorado de si mesmo; o instrumento que lhe possibilitava tal atividade era o saber racional, com o auxílio, dentre outras instituições, da escola. Essa, da cabeça aos pés, esteve e ainda está mergulhada naqueles mais triunfantes discursos iluministas: promover as condições para que os alunos desenvolvam sua autonomia, criticidade e protagonismo; fazer uso de saberes diversificados cujos resultados, eivados de ciência e racionalidade, dariam ensejo à emancipação política e à liberdade social, à cidade justa e ao universalismo (SILVA, 1995).

A serviço desses desejos, a escola transformou-se não apenas em mero veículo de distribuição do projeto moderno, pois ao centralizar nas suas prerrogativas os famosos ideários do Século das Luzes, acabou por confundir-se com o "[...] próprio projeto da Modernidade. É a instituição moderna por excelência" (SILVA, 1995, p. 244). Como uma verdadeira usina de subjetividade, vem-lhe sendo requisitado desde então determinados tipos de sujeitos necessários a certos tempos e espaços. Malgrado continue ancorada em mantras edificantes e nobres - a ordem, o progresso, a igualdade, a justiça, a paz... -, o fato é que da escola se espera que atenda ao que lhe é solicitado, e 
é justamente pela plasticidade desses espíritos morais que eles se ajustam a projetos de ideologias tão díspares quanto conflitantes. É por tal perspectiva que, no frigir dos ovos, a maioria das discussões pedagógicas, à direita ou à esquerda da ideologia acabam orbitando em torno de como fazer a "[...] criança transformar-se num cidadão útil através de estágios de crescimento" (JONES, 2011, p. 113).

Então, se entre o passado e o presente dos textos geoescolares encontramos menos diferenças e muito mais semelhanças, resta-nos inferir que a subjetividade aspirada por aqueles que escrevem sobre ensino de Geografia vem sendo, simplesmente, conveniente, e isso pode ser aplicado tanto àquela passagem do setor primário ao secundário da economia na primeira metade do século XX, quanto à mudança de ênfase que estaríamos vivendo de uma produção fordista de massa para uma sociedade pósindustrial (DE MASI, 2000), cujo principal substrato é a transferência do modelo de fábrica para o da empresa (DELEUZE, 2013). Vejamos isso em maiores detalhes.

O modelo de fábrica concentra seus trabalhadores, distribui-os espacialmente para ordená-los no tempo, a fim da transformação mais rápida e eficiente de matériaprima. Já a empresa não compra a matéria-prima nem vende produtos acabados: ao contrário, ela exerce um capitalismo de sobreprodução, que vende serviços e não compra bens materiais, mas ações; portanto, a configuração empresarial é espacialmente dispersiva, ao invés de enraizada (DELEUZE, 2013). Esse arranjo acarreta uma intensificação da competitividade nas relações entre os indivíduos, que se veem forçados a contrapor-se uns aos outros para atingirem os resultados e serem valorizados pelo seu mérito. A empresa supervaloriza a meritocracia, constantemente realimentada: os prêmios e as metas mudam em consonância com a volatilidade da sociedade de consumo e, em vista disso, a subjetividade não é dada de antemão, mas de modo dinâmico. Consequentemente, a formação permanente obriga cada indivíduo a começar do zero inúmeras vezes, realizando seguidos processos de desaprendizagem (HARDT, 2000). Quem pensou que qualquer semelhança desses princípios com o lema do "aprender a aprender" não é mera coincidência seguramente pensou certo, porquanto esse possui no bojo da sua concepção uma aprendizagem significativa que institui certa moldagem aos requisitos específicos de qualificação da força de trabalho contemporânea.

Nessa linha de raciocínio, Bauman (1999) explica que os trabalhadores são treinados menos para saber e mais para esquecer, afinal a competição não cessa e a inovação constante é obrigatória; não devem, logo, habituar-se com turnos diários e ambientes fixos, já que o emprego é instável e as localizações produtivas são flutuantes; o envolvimento emocional com os seus colegas, por sua vez, é reduzido, posto que eles são temporários. Com pessimismo, Harvey (2012, p. 210) conclui que os sujeitos, "[...] em vez de adquirirem uma habilidade para toda a vida, podem esperar ao menos um surto, senão muitos, de desabilitação e reabilitação no curso da vida".

Das microfísicas teias que vêm sendo constituídas nos ditos e escritos do ensino de Geografia, vamos percebendo um discurso que não é de resistência ou revolução, mas que se coloca ao lado de uma correia transmissora que tem no trabalho flexível sua pedra principal de toque. Por isso, naturalmente defende a educação continuada como mola propulsora de valorização dos espaços escolares; da mesma forma, tende a construir técnicas que façam da avaliação uma prática continuada, ao invés dos exames de terminalidade específica que instituíam as normas e classificavam os discentes de um estágio ao outro de desenvolvimento. É dessa lógica que vemos ascender pacificamente a emergência de uma "[...] terrível formação permanente, de um controle contínuo se exercendo sobre o operário-aluno ou o executivo-universitário" (DELEUZE, 2013, p. 220). No entanto, o que acaba sendo o nó górdio dessa questão - e que poderia ser até 
mesmo considerado contraditório - é que as pedagogias progressistas geoescolares acabam por legitimar a presença dos ideários capitalistas que imaginavam ser antagonistas. Por esse âmbito, malgrado possuam uma roupagem inocente e guiada por boas intenções - "[...] produzir crianças, homens e mulheres conscientes, livres, críticos, emancipados, desalienados, essencialmente humanos, etc." (CORAZZA, 1995, p. 15) -, esses discursos intensificam aqueles valores de cunho, comumente, neoliberais. Há nisso tudo "[...] uma salada mal-digerida de intenções progressistas com argumentos marcadamente conservadores" (COSTA, 2013, p. 61).

Quem diria que o desejo sincero de formar sujeitos críticos na verdade terminaria por se alinhar às necessidades da economia, provisórias? Quem diria que estimular o pensamento e a atitude autônoma daria guarida a um crescente individualismo, útil à competitividade e à meritocracia dos organismos de controle neoliberais? Quem diria que as posições heroicas do ensino de Geografia contribuiriam para atitudes, não raramente, reacionárias e excludentes?

Por agora, alguém já deve estar se perguntando se poderia ser diferente ou se, ao fim e ao cabo, o contraponto seria possível. Sem os perigos das milagrosas soluções que o Iluminismo universalmente prescreveu, gostaria de sinalizar uma capilar maneira de, talvez, rechaçar parte dessas ladainhas psicopedagógicas provenientes do Ensino de Geografia Régio: entender como, em discurso, elas vêm funcionando no que tange às práticas da sala de aula.

\section{ENFIM: COMO ESSE DISCURSO SE ORGANIZA ESTRATEGICAMENTE NO BOJO DAS DIDÁTICAS CONTEMPORÂNEAS?}

Levado a bom termo, o ensino de Geografia é um entre outros tantos alvos da fusão entre as pedagogias ativas, as metodologias participativas e as psicologias escolares. Por conseguinte, vem lhe chegando requisições de que não se separe da economia, mas que se coloque a serviço dela com maestria. Com efeito, é por meio da simbiose entre os valores do individualismo, do consumismo e da competitividade, que assistimos, desde a primeira metade do século XX, à emergência de propostas para a sala de aula que tem no discente homo oeconomicus sua maior centralidade. Alguns exemplos, nesse sentido, são nítidos.

Dos textos pedagógicos como aqueles encontrados no Boletim Geográfico às principais prescrições curriculares hodiernas, é possível identificar ao longo das últimas décadas o recrudescimento de pedagogias que, voltadas para a aprendizagem, desejam intensificar a motivação do aluno e a sua autonomia. Um exemplo para tal afirmação é dado por Varela (1999), que se refere à introdução dos mais variados recursos lúdicos e tecnológicos, nada mais do que jogos simulados da realidade que buscam resolver virtualmente problemas da vida social; com a transmissão de saberes em segundo plano, os espaços escolares seriam, muitas vezes, semelhantes a "[...] parques de alucinado entretenimento" (VARELA, 1999, p. 104-105). Veiga-Neto (2002) argumenta que tais didáticas se estreitariam à relação entre um consumidor e a ofertas de mercadorias e, nesse pressuposto, essa engenharia curricular tenderia por exortar a cultura do descarte e da transitoriedade. Não apenas isso, é verdade: temos os temas transversais, ancorados na interdisciplinaridade necessária às empresas; a matrícula eletiva por disciplinas, cuja consequência é a perda da identidade das escolas e sua subsequente despolitização, pois é transformada em um não-lugar; por fim, há um lugar privilegiado preenchido pelos projetos, que permitem ao aluno escolher aqueles que mais lhe interessam (VEIGANETO, 2002). Como resultado desses encaixes, os conteúdos passam a valer pela significância rápida e o "sentido" que podem evocar, acarretando nos discursos 
pedagógicos uma aversão aos conteúdos, pois a ideia-chave é a de que "A iniciativa individual e o processo de aprender a aprender são muito mais enfatizados do que o ensino, e devem voltar-se, sobretudo, para a inovação" (COSTA, 2009, p. 182). Entrementes, o docente é forçado a abandonar o papel de transmissor de saberes para ser um gestor de competências (PERRENOUD, 2000).

É interessante identificar que aprender, nesses pressupostos, significaria submeter-se às condições do meio e, por isso, haveria inclusive um sustentáculo teórico referendado pela epistemologia genética piagetiana, segundo a qual a inteligência é um órgão cuja função principal é a sua engrenagem adaptadora. Muitas das pedagogias progressistas, desse modo, alinhar-se-iam aos ditames da acumulação capitalista flexibilizada, afinal os ventos do mercado mudam constantemente de direção e caberia à força de trabalho acompanha-los ou estar disposta "[...] a aprender qualquer coisa, não importando o que seja, desde que seja útil à sua adaptação incessante" (DUARTE, 2001, p. 80). Mais vale que a escola estimule a formação de "[...] pessoas capazes de resolver problemas, como constituídas de subjetividades flexíveis, cujas fronteiras estão continuamente mudando" (POPKEWITZ, 1998, p. 120). Seguindo esse fio condutor é que podemos, igualmente, localizar no interior dessas práticas o incremento da chamada cultura do empreendedorismo, que se infiltra nos sistemas educacionais com o objetivo de forjar o sujeito microempresário, que investe sobre si mesmo, toma decisões, assume riscos e realiza cálculos, prognósticos e planejamentos; “[...] transmuta-se, assim, num indivíduo micro-empresa: Você S/A" (COSTA, 2009, p. 177).

$\mathrm{Na}$ medida em que didáticas como as pedagogias de projetos (nas quais se escolhe o que estudar), as metodologias ativas (simulando a realidade) e as competências e habilidades (necessidades contingentes da economia) se fundam no lema de capacitar os sujeitos para lidarem eficientemente em um quadro de incerteza econômica, é sem surpresas que se consegue concluir que tais propostas tendem a ser construídas, destruídas e reconstruídas no mesmo ritmo em que a obsolescência programada arremessa no lixo o que pouco antes utilizou e produziu. Trata-se da mesma situação em que se encontra aquele que trabalha, afinal ele deve ser "[...] mais dócil, fácil de moldar, cortar e enrolar, sem oferecer resistência” (BAUMAN, 1999, p. 112).

Ao aceitar o risco de pensar diferentemente do que se pensa, talvez possamos ver com maior limpidez para quais percursos vêm sendo direcionados os dizeres e fazeres ligados à Geografia da escola. Invertendo nossos óculos analíticos e virando um discurso de cabeça para baixo, quem sabe não nos assustaremos tanto quando, da próxima vez, ouvirmos o expert geoeducacional da vez proferindo que cabe ao pensamento geográfico forjar sujeitos críticos, cidadãos e autônomos por intermédio de múltiplas e inovadoras metodologias de ensino. Saberemos que sua fala não é nova e tampouco especial, mas um produto totalmente aquartelado ao regime de verdade de uma determinada época; que de surpreendentemente apenas possua, provavelmente, sua ingenuidade.

Esta escola que vivenciamos está mergulhada num regime de verdade e numa ordem discursiva condicionada às relações de poder de uma dada época. Bem mais do que um lugar de passagem obrigatória e socialização secundária, ela vem se destacando como um dos principais veículos de transmissão dos valores da economia capitalista pós-industrial. Com a emergência do neoliberalismo, cujo objetivo é submetê-la de joelhos às leis do mercado, sua notoriedade vem se expandindo com características inéditas.

Como um dos principais componentes curriculares, o ensino de Geografia opera seus saberes pedagógicos nesse aquartelamento, e o próprio conhecimento da longa faixa de tempo em que esses ditames vêm sendo fortalecidos torna mais complexa sua 
análise discursiva. Acompanhamos um sedimentado conjunto de ditos e escritos que nos foi dando subsídios para argumentar que o ensino de Geografia contemporâneo não se fez sob tábula rasa, ao gosto do idealismo dos seus pesquisadores ou sob as águas cristalinas de uma matriz de pensamento pedagógico. Ao contrário: trabalhou e se desenvolveu em meio às necessidades de uma época, visando forjar específicos tipos de sujeitos. Sinalizar esse panorama não significa dizer, é claro, que não houve ou não esteja havendo nas milhões de aulas de Geografia por esse país afora espaço para o pensamento crítico ou que se enraíze na diferença. No entanto, o fato é que, queira-se ou não, a economia de mercado é especialista em aproveitar-se de qualquer coisa, de forma que vem conseguindo vampirizar com excelência lemas aparentemente tão nobres quanto a cidadania e a liberdade.

\section{REFERÊNCIAS}

ALMEIDA, Laila Coelho de. Objetivos do ensino de Geografia na escola secundária. Boletim Geográfico, Rio de Janeiro, v. 20, n. 167, mar.-abri. 1962.

ARIÈS, Philippe. História social da criança e da família. Rio de Janeiro, RJ: LTC, 1981.

BACKHEUSER, Everaldo. O ensino da Geografia. Boletim Geográfico, Rio de Janeiro, v. 4, n. 43, out. 1946.

BATISTA, Bruno Nunes. A ordem do discurso geoescolar. Tese (Doutorado em Geografia). Instituto de Geociências, UFRGS. Porto Alegre, 2017a.

Como nos tornamos professores de Geografia: discurso ordenado, prática neoliberal. Revista Pedagógica, Chapecó, v. 19, n. 42, set-dez. 2017 b.

Pensar o ensino de Geografia como algo feito por comentaristas de textos sagrados. Educar em Revista, Curitiba, v. 34, n. 68, jan-mar. 2018.

BAUMAN, Zygmunt. Globalização: as consequências humanas. Rio de Janeiro: Zahar, 1999.

2011.

Bauman sobre Bauman: Diálogos com Keith Tester. Rio de Janeiro: Zahar,

CABRAL, Eddy Flores. O ensino de Geografia. Boletim Geográfico, Rio de Janeiro, v. 16, n. 145, jul.-ago. 1958.

CALLAI, Helena Copetti. Estudar o lugar para compreender o mundo. In: CASTROGIOVANNI, Antonio Carlos (Org). Ensino de Geografia: práticas e textualizações no cotidiano. Porto Alegre: Mediação, 2009.

CARVALHO, Delgado de. As três características do Ensino Geográfico. Boletim Geográfico, Rio de Janeiro, v. 2, n. 23, fev. 1945.

Didática das Ciências Sociais. Boletim Geográfico, Rio de Janeiro, v. 10, n. 108, maio-jun. 1952b. 
Didática das Ciências Sociais (continuação). Boletim Geográfico, Rio de Janeiro, v. 10, n. 110, set.-out. 1952c.

CARVALHO, Eloísa de. Notas de didáticas da Geografia. Boletim Geográfico, Rio de Janeiro, v. 18, n. 156, mai.-jun. 1960.

CASTELLAR, Sonia. Mudança na prática docente: a aprendizagem em espaços nãoformais. In: CASTROGIOVANNI, Antonio Carlos; KAERCHER, Nestor André; REGO, Nelson. Geografia: práticas pedagógicas para o ensino médio (volume 2). Porto Alegre: Penso, 2011.

CASTROGIOVANNI, Antonio Carlos. Para entender a necessidade de práticas prazerosas no ensino de Geografia na pós-modernidade. In: REGO, Nelson; CASTROGIOVANNI, Antonio Carlos; KAERCHER, Nestor André. Geografia: práticas pedagógicas para o Ensino Médio. Porto Alegre: Artmed, 2007.

CAVALCANTI, Lana de Souza. A geografia escolar e a cidade: Ensaios sobre o ensino de Geografia para a vida urbana cotidiana. Campinas, SP: Papirus, 2008.

Jovens escolares e suas práticas espaciais cotidianas: o que tem isso a ver com as tarefas de ensinar Geografia? In: In: CALLAI, Helena Copetti (Org). Educação Geográfica: reflexão e prática. Ijuí: Ed. Unijuí, 2011.

O ensino de Geografia na escola. Campinas, SP: Papirus, 2012.

CORAZZA, Sandra Mara. Poder-saber e ética da escola. Ijuí: Ed. Unijuí, 1995.

História da infantilidade: a-vida-a-morte e mais-valia de uma infância sem fim. Tese (Doutorado em Educação). Faculdade de Educação, UFRGS. Porto Alegre, 1998.

COSTA, Sylvio de Sousa Gadelha. Governamentalidade neoliberal, Teoria do Capital Humano e Empreendedorismo. Educação \& Realidade, Porto Alegre, v. 34, n. 2, mai.ago. 2009.

COSTA, Márcio da. A educação em tempos de conservadorismo. In: GENTILI, Pablo (Org.). Pedagogia da exclusão: crítica ao neoliberalismo em educação. Petrópolis, RJ: Vozes, 2013.

COSTELLA, Roselane Zordan; REGO, Nelson. Em que momento um aluno aprende geografia. In: CASTROGIOVANNI, Antonio Carlos; KAERCHER, Nestor André; REGO, Nelson. Geografia: práticas pedagógicas para o ensino médio (volume 2). Porto Alegre: Penso, 2011.

CUNHA, Murillo Alves da. O planejamento no ensino da Geografia. Boletim Geográfico, Rio de Janeiro, v. 20, n. 169, jul.-ago. 1962.

DAMASCENO, Daury Fontenelle. Algumas considerações sobre o emprego do material didático no ensino da Geografia. Boletim Geográfico, Rio de Janeiro, v. 24, n. 185, mar.-abri. 1965. 
DE MASI, Domenico. O ócio criativo: entrevista à Maria Serena Palieri. Rio de Janeiro: Sextante, 2000.

DELEUZE, Gilles. Conversações (1972-1990). São Paulo: Editora 34, 2013.

DUARTE, Newton. Vigotski e o "aprender a aprender": críticas às apropriações neoliberais e pós-modernas da teoria vigostskiana. Campinas, SP: Autores Associados, 2001.

DURKHEIM, Émile. A evolução pedagógica em França. Educação, sociedade \& culturas, Lisboa, v. 1, n. 2, 1994.

FICHEUX, M. R. Ensino da Geografia II. Boletim Geográfico, Rio de Janeiro, v. 8, n. 86, mai. 1950a.

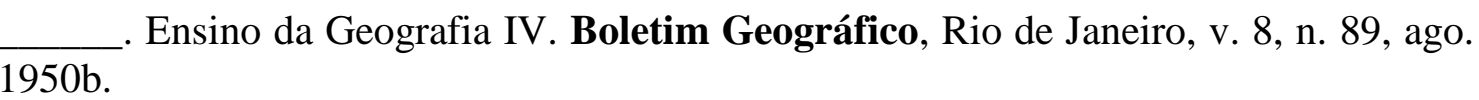
1950c.

Ensino da Geografia III. Boletim Geográfico, Rio de Janeiro, v. 8, n. 87, jun.

FONSECA, James B. Viera da. O Ensino da Geografia. Boletim Geográfico, Rio de Janeiro, v. 13, n. 129, nov.-dez. 1955.

FOUCAULT, Michel. A ordem do discurso: aula inaugural no Collège de France pronunciada em 2 de dezembro de 1970. São Paulo: Edições Loyola, 1996.

Ditos e escritos II: Arqueologia das ciências e histórias dos sistemas de pensamento. Rio de Janeiro: Forense Universitária, 2000.

A verdade e as formas jurídicas. Rio de Janeiro: NAU Editora, 2002.

A arqueologia do saber. Rio de Janeiro: Forense Universitária, 2008.

GAUTHIER, Clermont. O século XVII e o problema do método no ensino ou o nascimento da Pedagogia. In: GAUTHIER, Clermont; TARDIF, Maurice (Orgs.). A pedagogia: teorias e práticas da Antiguidade aos nossos dias. Petrópolis, RJ: Vozes, 2010 .

HARDT, Michael. A sociedade mundial de controle. In: ALLIEZ, Eric. Gilles Deleuze: uma vida filosófica. São Paulo: Editora 34, 2000.

HARVEY, David. Condição pós-moderna: uma pesquisa sobre as origens da mudança cultural. São Paulo: Edições Loyola, 2012.

JONES, David Martin. Foucault e a possibilidade de uma pedagogia sem redenção. In: SILVA, Tomaz Tadeu da (Org.). O sujeito da educação: estudos foucaultianos. Petrópolis, RJ: Vozes, 2011. 
LA BLACHE, Vidal de. A Geografia na escola primária. Boletim do Conselho Nacional de Geografia, Rio de Janeiro, v. 1, n. 1, abri. 1943.

KANT, Immanuel. Resposta à questão: o que é Esclarecimento? Cognitio, São Paulo, v. 13, n.1, jan.-jun. 2012.

MAFFESOLI, Michel. Mediações simbólicas: a imagem como vínculo social. In: MARTINS, Francisco Menezes; SILVA, Juremir Machado da (Orgs). Para navegar no século XXI. Porto Alegre: Sulina/Edipucrs, 2003.

MEYNIER, A. Os problemas do ensino da Geografia nos estabelecimentos de segundo grau na França. Boletim Geográfico, Rio de Janeiro, v. 12, n. 123, nov.-dez. 1954.

MONBEIG, Pierre. A Geografia no Ensino Secundário. Boletim Geográfico, Rio de Janeiro, v. 13, n. 127, jul.-ago. 1955.

PADILHA, Fernando Araújo. O estudo dirigido em Geografia. Boletim Geográfico, Rio de Janeiro, v. 22, n. 177, nov.-dez. 1963.

PEDROSO, Tabajara. A Geografia no curso secundário (segunda parte). Boletim Geográfico, Rio de Janeiro, v. 25, n. 194, nov.-dez. 1966.

PERRENOUD, Philippe. 10 novas competências para ensinar: convite à viagem. Porto Alegre: Artmed, 2000.

PINTO, Maria Magdalena Vieira. Orientação metodológica para uso do atlas geográfico escolar. Boletim Geográfico, Rio de Janeiro, v. 22, n. 178, jan.-fev. 1964a.

O ensino da Geografia em face da Lei de Diretrizes e Bases. Boletim Geográfico, Rio de Janeiro, v. 22, n. 180, mai.-jun. 1964b.

POPKEWITZ, Thomas S. Reforma educacional e construtivismo. In: SILVA, Tomaz Tadeu da (Org). Liberdades reguladas: a pedagogia construtivista e outas formas de governo do eu. Petrópolis, RJ: Vozes, 1998.

ROMANELli, Otaíza de Oliveira. História da educação no Brasil (1930-1973). Petrópolis, RJ: Vozes, 1986.

SANTOS, Maurício Silva. O ensino da Geografia no curso secundário noturno. Boletim Geográfico, Rio de Janeiro, v. 22, n. 179, mar.-abril. 1964.

SILVA, Tomaz Tadeu da. O projeto educacional moderno: identidade terminal? In: VEIGA-NETO, Alfredo (Org.). Crítica pós-estruturalista e educação. Porto Alegre: Sulina, 1995.

VARELA, Julia. Categorias espaço-temporais e socialização escolar: do individualismo ao narcisismo. In: COSTA, Marisa Vorraber (Org.). Escola básica na virada do século: cultura, política e currículo. São Paulo: Cortez, 1999. 
VEIGA-NETO, Alfredo. Michel Foucault e educação: há algo de novo sob o sol? In: VEIGA-NETO, Alfredo (Org.). Crítica pós-estruturalista e educação. Porto Alegre: Sulina, 1995.

De geometrias, currículos e diferenças. Educação \& Sociedade, Campinas, v. 23, n. 79, 2002.

Faces da diferença. Ponto de vista, Florianópolis, n. 5, 2003. ago. 2012.

É preciso ir aos porões. Revista Brasileira de Educação, v. 17, n. 50, maio-

VIDAL, Diana Gonçalves. Escola nova e processo educativo. In: LOPES, Eliana et all (Orgs). 500 anos de educação no Brasil. Belo Horizonte: Autêntica, 2003.

XAVIER, Libânea Nacif. Para além do campo educacional: um estudo sobre o Manifesto dos Pioneiros da Educação Nova (1932). Bragança Paulista: EDUSF, 2002.

WEISS, Arthur Bernardes. Didática da Geografia. Boletim Geográfico, Rio de Janeiro, v. 19, n. 161, mar.-abri. 1961.

O problema da motivação no ensino da Geografia. Boletim Geográfico, Rio de Janeiro, v. 20, n. 168, mai.-jun. 1962.

ZAMORANO, Mariano. O ensino da Geografia na escola secundária. Boletim Geográfico, v. 28, n. 212, set.-out. 1969.

VESENTINI, José William. Realidades e perspectivas do ensino de Geografia no Brasil. In: VESENTINI, José William (org.). O ensino de Geografia no século XXI. Campinas: Papirus, 2004. 